\title{
Correspondence
}

\section{Submaximal exercise testing early after myocardial infarction}

Sir,

In the paper by Sullivan et al (1984; 52: 147-53), I was astonished to read that the ST segment elevation was the only exercise test variable predicting cardiac death in postmyocardial infarction patients. This phenomenon occurs with monotonous regularity in patients with even a minor degree of ST segment elevation in the resting 12 lead electrocardiogram soon after myocardial infarction. ${ }^{1}$ To my mind, the only conclusion from this paper is that routine postinfarction stress testing need not be performed in the first place.

The authors' classification of infarcts as transmural and non-transmural on the basis of $Q$ waves ascribes to the 12 lead electrocardiogram the accuracy which the latter simply does not have. ${ }^{2}$ Their analysis of cardiac events for the two groups of infarcts showed no significant differences, for reasons that have long ago become obvious. ${ }^{3}$

George Nikolic,

Woden Valley Hospital,

Woden,

Australia.

\section{References}

1 Nikolic G, Sugiura T, Spodick DH. Self-predicting stress tests. Br Heart $\mathcal{F}$ 1982; 47: 559-62.

2 Spodick DH. Q-wave infarction versus S-T infarction. Am f Cardiol 1983; 51: 913-5.

3 Phibbs B. "Transmural" versus "subendocardial" myocardial infarction: an electrocardiographic myth. $\mathcal{f}$ Am Coll Cardiol 1983; 1: 561-4.

This letter was shown to the authors, who reply as follows:

Sir,

In his carefully argued criticism of our paper Dr Nikolic cites his own study ${ }^{1}$ as evidence that ST seg- ment elevation on exercise occurs with "monotonous regularity" but it actually occurred in only $10 \%$ of 50 patients. The finding had been predicted in nine of the 45 tests which were analysed and possibly also in some of those which were excluded because a definite end point was not reached. We were not told the subsequent clinical progress of these patients.

Classification of patients by presence or absence of $Q$ waves is clearly a simplification, but significant differences between these groups have been described. ${ }^{2}$ Since ST segment changes alone are highly associated with non-transmural damage ${ }^{2}$ it seems reasonable to classify patients in this way when considering the significance of further changes induced by exercise.

The possible prognostic significance of different abnormalities during postinfarction stress testing is still unknown and the place of this procedure in clinical management will only become clear as more series are published. ${ }^{3}$ It would be most unusual if all studies on different patient populations produced identical results, and the answers will certainly remain unknown if no more studies are carried out.

\section{D Sullivan, D W Davies, Edgar Sowton, Guy's Hospital, London SE1 9RT.}

\section{References}

1 Nikolic G, Sugiura T, Spodick DH. Self-predicting stress tests. Br Heart $\mathcal{F}$ 1982; 47: 559-62.

2 Freifeld AG, Schuster EH, Bulkley BH. Nontransmural versus transmural mycardial infarction. A morphologic study. Am F Med 1983; 75: 423-32.

3 Jennings K, Reid DS, Hawkins T, Julian DJ. Role of exercise testing early after myocardial infarction in identifying candidates for coronary surgery. $\mathrm{Br} \mathrm{Med} \mathcal{F} 1984$; 288: $185-8$. 